\title{
CONTRIBUTIONS

\section{Two new species of the genus Curranosia PATERSON, 1957 (Diptera: Muscidae) from the Afrotropical Region}

\author{
With 2 figures
}

\section{EBERHARD ZIELKE ${ }^{1}$}

1 Institute of Biodiversity and Ecosystem Research, Bulgarian Academy of Sciences, 1 Tsar Osvoboditel Blvd, 1000 Sofia, Bulgaria. - eo.zielke@abv.bg

Published on 2020-06-23

DOI:10.21248/contrib.entomol.70.1.197-202

\begin{abstract}
Curranosia vanemdeni spec. nov. is described from Kenya. The species is characterized by features such as protruding mouthparts, slender proboscis and an anterior seta on mid tibia, which were not previously known to occur in this genus. Curranosia wyatti spec. nov., collected in The Gambia differs from other Curranosia species by wing colour, absence of white dusted markings on the presutural mesonotum, and differences in the numbers of large setae of the body, characters that are more common for the differentiation of species of the genus.
\end{abstract}

\section{Taxonomic acts}

Curranosia vanemdeni spec. nov. - urn:lsid:zoobank.org:act:192F65AF-3E14-4DDE-921C-DB840B8A06B4

Curranosia wyatti spec. nov. - urn:lsid:zoobank.org:act:971D4E89-CCE4-471D-BAF2-6703B1766324

\section{Key words}

Insecta, Muscinae, Curranosia vanemdeni spec. nov., Curranosia wyatti spec. nov., comparison, East Africa, Kenya, West Africa, The Gambia.

\section{Zusammenfassung}

Curranosia vanemdeni spec. nov. wird von Kenia beschrieben. Die Art ist durch Merkmale wie vorstehende Mundpartie, auffallend schlanker Proboscis und eine vordere Borste auf der mittleren Tibia charakterisiert. Taxonomische Merkmale, die bisher von Arten dieser Gattung nicht bekannt sind. Curranosia wyatti spec. nov. stammt von Gambia und unterscheidet sich von den anderen Curranosia Arten durch gattungs-typische Merkmale wie Körperfarbe, fehlende weiß bestäubte Areale auf dem vorderen Teil des Mesonotums und Unterschiede in der Anzahl der großen Körperborsten. 


\section{Introduction}

PATERson removed 1957 three species of the genus Orthellia Robineau-Desvoidy, 1863 to the newly described genus Curranosia because of very specific structures of the phallosome and bare infra alar bulla (greater ampulla). Both features are not present in all the other Orthellia species (now Neomyia WALKER, 1859). Four new Curranosia species were described in the 1970s (ZIELKe 1971a, 1971b, 1972, 1974) and since then, apparently no further species was added to the genus. For example, the seven species assigned to the genus were also listed by PONT 1980 in the catalogue of Afrotropical Diptera and Nihei \& CARvalho (2009) mentioned in their paper on the genera of Muscini flies of the world as well, that the genus Curranosia contains seven species but without naming these individually.

The recent examination of undetermined Muscidae of the collection of The Natural History Museum, London (NHM) which had been assigned in previous years provisionally to the genus Neomyia, revealed eleven specimens that, like all other specimens of the genus, had setulose hairs present on the suprasquamal ridge. But in contrast to the Neomyia species there were no setulae on the infra alar bulla. The flies obviously belonged to the genus Curranosia. Two of the males are each characterized by a combination of taxonomic features that has not yet been observed in the genus. Each male is therefore considered a representative of a new species. They are described below as Curranosia vanemdeni spec. nov. and Curranosia wyatti spec. nov. The other nine specimens found are listed as well.

\section{Materials and methods}

Keys to the Muscini of the Afrotropical Region (ZiELke 1971a) and the descriptions of the new Curranosia species (ZIELKE 1971b, 1972, 1974) were used for identification. Standard terminologies as applied in the Manual of Central European Muscidae (Gregor et al. 2016) are predominantly used for the descriptions. External morphological features were examined using a ZEISS Stemi 2000-C stereomicroscope, for illustrations an AxioCam ERc5s camera and for further processing Helicon Focus 6 and Adobe Photoshop CS2 have been applied. Body length was measured in millimeters $(\mathrm{mm})$.The inscription of the locality labels of the identified specimens are reproduced verbatim and are in general self-explaining. Additional comments are made if pertinent. All flies listed below are stored in the Entomological collection of NHM, London.

\section{Identified Curranosia species}

\author{
Curranosia gemma (BIGOT, 1878)
}

Material examined: $1{ }^{\star}$, Kenya, Kakamega Forest $5.100 \mathrm{ft}$., $0^{\circ} 15^{\prime} \mathrm{N} 34^{\circ} 52^{\prime} \mathrm{E}, 1972-01-18$ - 22, leg. C. F. Huggins, B. M. 1972-468; 1 \& Nigeria, Ikorodu Lagos, 16.10.1974, leg. M. A. Cornes; 1 + W. Africa, Obuasi Ashanti (Ghana), 1907-11-24, Dr. W. M. Graham, 1908-245, Caught on leaf in bush.

The female collected in Nigeria, Lagos is rather small with a body length of about $5 \mathrm{~mm}$. C. gemma is widely distributed in the Afrotropical Region and has been reported from Angola, Democratic Republic of Congo, Equatorial Guinea, Ghana, Liberia, Mozambique, South Africa and Uganda, (Zielke 1971a), from Nigeria (Zielke 1972) and Ivory Coast (ZIELKE 1974) and is additionally listed from Guinea-Bissau, Sudan and Tanzania (PonT 1980). It seems that the species has not been reported yet from Kenya.

\section{Curranosia prima (CURRAN, 1935)}

Material examined: $1 \sigma^{*}, 1$, Sierra Leone, 1924, leg. B. Blacklock, Presented by Liverpool Sch. Trop. Med. B. M. 1971-458; 1 \% , Kenya, Kakamega Forest $5.100 \mathrm{ft}$., $0^{\circ} 15^{\prime} \mathrm{N} 34^{\circ} 52^{\prime} \mathrm{E}$; 1972-01-18 - 22, leg. C. F. Huggins, B. M. 1972-468.

The species is known from Cameroon, Liberia, Mozambique and Zimbabwe (Zielke 1971a), from Nigeria (Zielke 1972) and Ivory Coast (Zielke 1974) and according to Pont (personal communication, 2018) it is also known from Democratic Republic of Congo, Ghana, Equatorial Guinea and Tanzania. The species has obviously not been reported yet from Sierra Leone and Kenya.

\section{Curranosia spekei pilarara (SNYDER, 1951)}

Material examined: $\sigma^{\star}$, Uganda, Ruwenzori Range, Kilembe 4.000 ft.; Dec. 1934 - Jan. 1935, F. W. Edwards, B. M. E. Afr. Exp. B. M. 1935-203; 1 †, Kenya, Kakamega Forest $5.100 \mathrm{ft} ., \quad 0^{\circ} 15^{\prime} \mathrm{N} 34^{\circ} 52^{\prime} \mathrm{E} ; \quad 1972-01-18$ - 22, leg. C. F. Huggins, B. M. 1972-468. Male bears two identification labels which read "(Pyrellia) ơ bonnarius van Emden det. 1942" and "Orthellia sp. nr. distincta, van Emden det. 1942".

This subspecies of Curranosia spekei (JAENNICKE, 1867) has been reported from Democratic Republic of Congo and Kenya (Zielke 1971a), as well as from South Africa and Tanzania (Pont 1980). Uganda seems to be a new record for the species. 
Curranosia vanemdeni spec. nov.

urn:Isid:zoobank.org:act:192F65AF-3E14-4DDE-921C-DB840B8A06B4

Material examined: $\sigma^{\top}$ holotype (Fig. 1) is marked with following labels: "Kenya Colony, 1933, zebra dung, C. B. Symes; Pres. by Com. Inst. Ent. B. M. 1950-323" and "Pyrellia sp. n.? van Emden, det. 1940".

The specimen is somewhat dirty, the right mid leg is lacking, and the membrane of the left wing is slightly torn. The damage did not hamper the identification of the specimen.

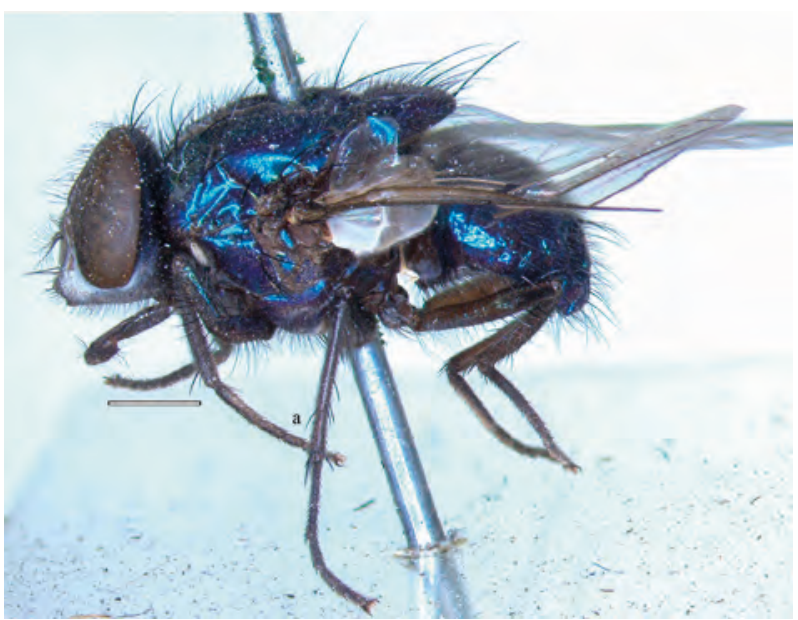

Fig. 1: Curranosia vanemdeni spec. nov., male holotype, lateral view $($ bar $=1 \mathrm{~mm})$. $\mathrm{a}$ = anterior seta of mid tibia.

Description (male): Head ground-colour ochrebrownish, silver-white dusted. Eyes large, practically bare, anterior facets near to frons distinctly enlarged, facets of outer side of eye smaller; shortest distance between eyes slightly shorter than diameter of anterior ocellus. Frontoorbital plates touching over almost all of their length, width of fronto-orbital plate at shortest distance between eyes about as wide as diameter of the adjacent facets. Parafacials in upper half almost parallel-sided, dilating in lower half, at level of insertion of arista to postpedicel about as broad as diameter of anterior ocellus. In profile mouthparts protruding, upper mouth margin beyond profrons (Fig. 1). Width of gena at lowest eye margin about half the length of postpedicel. Face, fronto-orbital plates, parafacials and genae brownish and, except upper two thirds of fronto-orbital plates, silver-white dusted. Antennal segments dark brown, postpedicel brownishgrey dusted. Postpedicel short, about 2.5 times as long as broad and twice as long as pedicel. Arista brown, at basis somewhat thickened, barely 1.5 times as long as length of postpedicel, longest dorsal hairs of arista more than twice as long as width of postpedicel. Fronto-orbital plate throughout its length with a row of densely standing setulose hairs, the hairs in front of ocellar tubercle either inclinate or proclinate, hairs at level of ocellar tubercle shorter and more reclinate. Parafacial bare. Vibrissal setae strong and distinctly longer than longest surrounding peristomal setae. Ventral part of gena covered with short setulose hairs, postgena and post-occipital surface with longer dark setulose hairs. Proboscis (Fig. 1) long and conspicuously slender, at least six times as long as its diameter, dark, prementum with some greenish-blue reflections; labella rather short, almost knob-like; palpus brown, basal half very slender, apically distinctly clavate, about as long as prementum.

Thorax with mesonotum and anterior pleura depending on quality of light shining greenish-blue or predominantly blue, at some points of view with weak violet reflections. When viewed from behind presutural part of mesonotum with a broad whitish dusted stripe reaching the transverse suture. Scutellum of about same colour as mesonotum but somewhat more dark bluish. Posterior pleura predominantly shining brownish, depending on angle of viewing with some violet-bluish reflections, all pleura at some points of view more or less greyish dusted. Anterior spiracle contrasting white (Fig. 1), posterior spiracle brown. Dorsocentrals 2+4; acrostichals $0+1$, three postpronotal setae, the inner one only slightly shorter than the outer ones; two notopleural setae, posterior one slightly longer, notopleuron densely haired; pre-alar seta about two thirds as long as posterior notopleural seta; one intra-alar seta. Infra-alar bulla without distinct setulae, suprasquamal ridge with fine, but distinct seta-like hairs, golden-yellow coloured. Prosternum bare, anepimeron with longer hairs on the posterior surface. Proepimeral area and katepimeron bare; meron with several hairs below posterior spiracle. Katepisternals $1+3$, the lower two very close to the posterior seta and shorter. Anepisternum with a short but distinct seta anteriorly almost opposite to anterior notopleural seta, posterior margin with a row of 6 or 7 well-developed setae and some much shorter interstitial hairs. Scutellum with a pair each of strong apical, strong lateral and strong subapical setae, basal setae much smaller and barely distinguishable from long ground hair; lateral surface and margin to the ventral surface of scutellum distinctly haired.

Wing membrane hyaline and uniformly covered with microtrichia, cross-veins and surrounding membrane not infuscate. Tegula dark brownish, basicosta contrasting yellowish, veins yellowish to brownish. Costal spine not much longer than surrounding bristles. Distal end of stem vein dorsally and ventrally with a hair-like seta; radial node and vein $\mathrm{R}_{4+5}$ dorsally with a row of strong setulae reaching cross-vein $\mathrm{r}-\mathrm{m}$, ventrally with weaker setulae reaching midway to $r-m$. Vein $M_{1}$ apically distinctly curved to vein $\mathrm{R}_{4+5}$, the distance between the two veins at wing margin distinctly less than the length of cross-vein $\mathrm{r}-\mathrm{m}$, the latter clearly basad of the point where vein $R_{1}$ enters costa; distal cross-vein $\mathrm{dm}$-cu sinuous and oblique. Calypters whitish transparent, lower calypter at some angles of view with a weak yellowish-brownish shimmer, margins predominantly whitish, lower calypter about twice as long as upper calypter. Basis of haltere brownish, stem yellow, knob predominantly whitish (Fig. 1).

Legs all brown, femora at some points of viewing with greenish-blue reflections, tibiae at some points of view 
with a yellowish-ochre shine. Pulvilli and claws clearly shorter than the corresponding tarsomere. Fore femur with complete rows of posterodorsal and posteroventral setae. Fore tibia without median posterior seta. Mid femur with complete rows of anteroventral and posteroventral setulose hairs, length of hairs conspicuously long at basis, decreasing over the length of femur and rather short at apical third, at middle third of femur a row of distinct but not very long anterior setae, preapically three strong posterodorsal setae. Mid tibia with four posterior setae at least as long as diameter of tibia, a conspicuous posteroventral seta at least twice as long as diameter of tibia distally at the middle third of tibia and one distinct anterior seta at apical third (Fig. 1), longer than diameter of tibia. Hind coxa bare on posterior surface. Hind femur with a dense row of strong anterodorsal setae and complete rows of long anteroventral and posteroventral seta-like hairs, partly slightly curved, and at basal half with several long ventral hairs between the two rows, preapically two strong posterior to posterodorsal setae. Hind tibia with a row of about six anterodorsal setae somewhat varying in length but not as long as diameter of tibia, two distinct anteroventral setae at middle third, at apical third a strong and long posterodorsal seta.

Abdomen without specific pattern, depending on quality of light shining dark bluish-green or bluish with strong reflections and depending on point of viewing with small flexible glossy ochre-brownish to brownish-violet areas changing to bluish reflections when angle of light is changed. Anterior half of syntergite $1+2$ dorsally and laterally more shining brownish. Tergite 3 with some stronger marginal setae, tergites 4 and 5 with complete rows of distinct marginals and laterally with few longer discals. Ventral parts of tergites predominantly concolorous with dorsal parts. Sternite 1 densely haired, sternites mainly brownish.

Male genitalia. The species is distinguished from the known species of the genus by several taxonomic characteristics. Therefore it has been deemed wiser to refrain from extracting the genitalia to avoid inflicting damage on the hitherto only available specimen.

Measurements. Length of body about $6 \mathrm{~mm}$; length of wing about $6 \mathrm{~mm}$.

Etymology: The holotype had already been examined by van Emden in 1940 who did not identify the Muscidae down to species level but labelled the specimen as questionable Pyrellia spec. nov. Since this specimen is characterized by a combination of features, that did not match the valid criteria of the known Muscidae genera at that period, it proved to be difficult to identify the genus to which the specimen best fits. To acknowledge this attempt to find the most suitable genus for the specimen, the species is name is dedicated to van Emden. The name vanemdeni is a noun in the genitive case.
Diagnosis: The specimen of Curranosia vanemdeni spec. nov. runs in the key to Curranosia species (ZIELKE 1971a) to Curranosia spekei s. str. (JAENNICKE, 1867). Both species are distinguished by several taxonomic features, for example protruding mouthparts, a slender proboscis and anterior seta at the apical third of the middle tibia, complete row of long posteroventral setulose hairs and only two anteroventral setae on the posterior femur and in addition the mesonotum is marked only by a broad whitish dusted median longitudinal stripe in C. vanemdeni. In contrast to these, C. spekei s. str. has no strongly projecting mouthparts and the proboscis is not strikingly slender, there is no anterior seta on mid tibia and no complete row of long posteroventrals on hind femur, but hind tibia has 3-4 anteroventral setae and the surface of anterior part of mesonotum is intensely greyish-white dusted.

\section{Curranosia wyatti spec. nov. urn:Isid:zoobank.org:act:971D4E89-CCE4-471D-BAF2-6703B1766324}

Material examined: $\sigma^{t}$ holotype (Fig. 2) is marked with two labels. The first label bears the information: CK. 97, Keneba, Gambia, M. C. D. Speight, 1975-09-21, rainy season; and the second one reads: In Malaise trap by $4 \mathrm{ft}$. grass, between lawn \& Arachis crop.

The left hind tarsi are lacking.

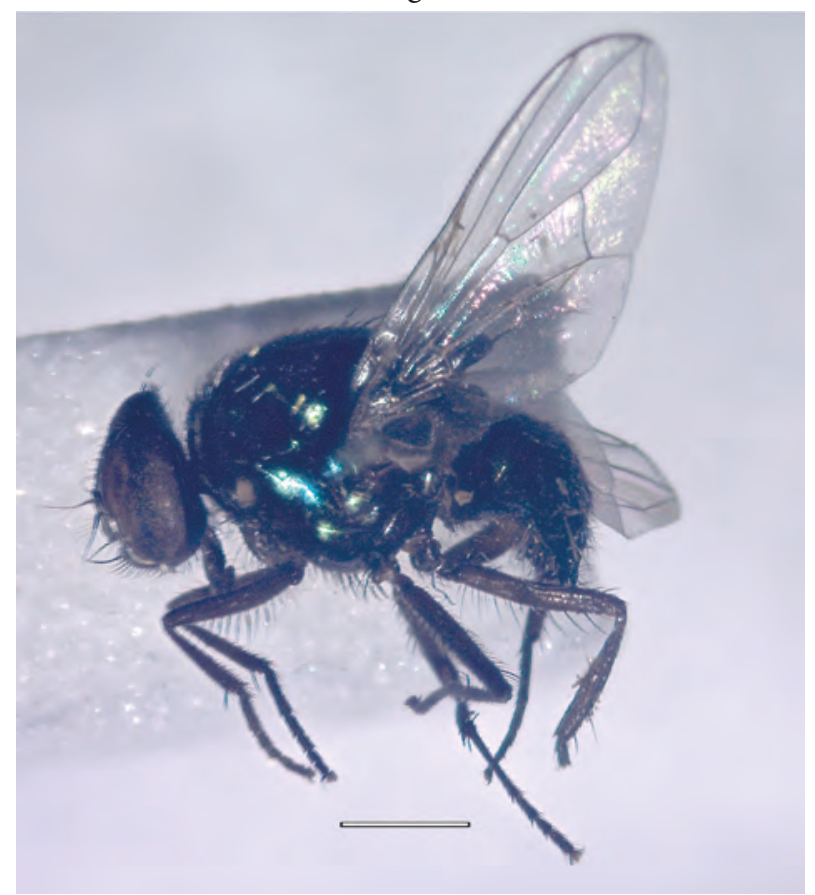

Fig. 2: Curranosia wyatti spec. nov., male holotype, lateral view (bar $=1 \mathrm{~mm})$.

Description (male): Head ground-colour dark brown to blackish, partly greyish-white dusted. Eyes large with some tiny hairs, anterior facets near to frons distinctly enlarged, facets of outer side of eye smaller; shortest distance between eyes barely twice the diameter of anterior ocellus. Fronto-orbital plates separated by narrow frontal vitta, almost as broad as anterior ocellus, width 
of fronto-orbital plate at shortest distance between eyes about as wide as diameter of the adjacent facets. Parafacial at level of base of antenna about as broad as anterior ocellus, dilating below all over the length to more than half the width of postpedicel. In profile upper mouth margin about in line with profrons. Depth of gena below lowest eye margin approximately equal to width of postpedicel. Face, fronto-orbital plate, frontal vitta, parafacial and gena dark brown or black, at some points of viewing face, gena, parafacial and anterior third of fronto-orbital plate whitish dusted. Antennal segments dark brown with some greyish-brown dust. Postpedicel about 3.3 times as long as broad and more than three times as long as pedicel. Arista dark brown, basal half somewhat thickened, rather short, at most 1.3 times as long as length of postpedicel, longest dorsal hairs of arista more than twice as long as width of postpedicel. Fronto-orbital plate all over its length with a row of setulose hairs, the hairs anterior to ocellar tubercle either inclinate or proclinate, at level of ocellar tubercle two shorter and more reclinate hairs. Parafacial bare. Vibrissal setae strong and more than twice as long as longest surrounding peristomal setae. Upper surface of gena bare or with some short hairs, lower part and margin with setulose hairs. Proboscis slender, about three times as long as its diameter, dark, prementum brown and shining; labella somewhat longer than depth of proboscis; palpus dark brown, slender, somewhat clavate, about as long as prementum.

Thorax. Ground-colour shining dark green, dorsally without white pollinosity. When viewed from behind mesonotum and scutellum shining green with some weak brass reflections without any whitish pattern. Anterior pleura shining green, posterior pleura predominantly shining brown, when viewed very much from the anterior the pleura appearing to be slightly greyish dusted. Anterior spiracle contrasting white (Fig. 2), posterior one brown. Dorsocentrals $2+3$, the anterior postsutural seta distinctly shorter than the posterior ones and the presutural dorsocentrals; acrostichals $0+1$, three postpronotal setae, the inner one shorter than the outer ones; two notopleural setae, posterior one slightly shorter, notopleuron densely haired; pre-alar seta at least half as long as posterior notopleural seta; one intra-alar seta. Infra alar bulla without setulae, suprasquamal ridge with fine, but distinct seta-like hairs at certain angle of light of golden-yellow colour. Prosternum bare, anepimeron with longer hairs on the posterior surface. Proepimeral area and katepimeron bare; meron with some hairs below posterior spiracle. Katepisternals $1+3$, the lower two very close to the posterior seta and shorter. Anepisternum with a distinct anterior seta about opposite to anterior notopleural seta and at posterior margin with a row of 6 strong setae, the longest one at the top of the row then decreasing in length and with only very few shorter interstitial hairs. Scutellum with a pair of strong apical and lateral setae, subapical setae about half as long as apical setae and basal seta hardly distinguishable from long setulose ground hair; lateral surface and margin to the ventral surface haired.

Wing. Membrane hyaline, uniformly covered with microtrichia, cross-veins and surrounding membrane not infuscate. Tegula dark brownish, basicosta yellowishbrown, veins yellowish to brownish. Costal spine hardly distinguishable from surrounding bristles. Distal end of stem vein dorsally with a short hair, ventrally with at least two setulae, one distinctly longer; radial node and vein $\mathrm{R}_{4+5}$ dorsally with a row of setulae almost reaching crossvein $\mathrm{r}-\mathrm{m}$, ventrally with a row reaching about midway to $r-m$. Vein $M_{1}$ apically distinctly curved to vein $R_{4+5}$ the distance between the two veins at wing margin at most half as long as the length of $\mathrm{r}-\mathrm{m}$. Cross-vein $\mathrm{r}-\mathrm{m}$ distinctly basad of the point where vein $\mathrm{R}_{1}$ enters costa; distal cross-vein dm-cu sinusoid and oblique. Upper calypter predominantly hyaline transparent with darker margin, lower calypter brownish and almost twice as long as upper calypter. Basis and stem of haltere brownish, knob yellowish-white.

Legs uniformly brown, depending on angle of view either dark brown or somewhat paler. Pulvilli and claws clearly shorter than the corresponding tarsomere. Fore femur with complete rows of posterodorsal and posteroventral setae. Fore tibia without median posterior seta. Mid femur with irregular rows of anteroventral and posteroventral setulose hairs, apart from one longer seta-like hair at basis the length of hairs barely as long as depth of femur at level of insertion, basal half of femur with a row of distinct but not very long anterior setae, preapically two strong posterodorsal setae. Mid tibia with about four short posterior setae, the middle one distinctly stronger, one strong posteroventral seta distally at middle third of tibia. Hind coxa bare on posterior surface. Hind femur with a row of strong anterodorsal setae and a row of anteroventral shorter setae at the apical half and somewhat longer hairs in the basal half, posteroventral surface at about middle third with approximately three longer seta-like hairs, preapically two strong posterior to posterodorsal setae. Hind tibia with a row of several short anterodorsal setae and one longer one opposite to two distinct anteroventral setae at apical half, at apical third a strong and long posterodorsal seta.

Abdomen. Without specific pattern, shining dark green with strong reflections. Depending on angle of view anterior half of syntergite $1+2$ shining brownish. When viewed from very much behind tergites 3 and 4 thinly greyish dusted. Tergites 3 and 4 laterally with some stronger marginal setae, tergite five with almost a complete row of distinct marginals and laterally with few longer discals. Ventral parts of tergites predominantly concolorous with dorsal parts. Sternite 1 with some setulose hairs, sternites predominantly brownish.

Male genitalia. The species is distinctly distinguished from the known species of the genus by several taxonomic characteristics. Therefore it deemed wiser to refrain from extracting the genitalia to avoid inflicting damage on the hitherto only available specimen. 
Measurements. Length of body almost $4 \mathrm{~mm}$; length of wing about $3.6 \mathrm{~mm}$.

Etymology: It is a pleasure to name this species after Nigel Wyatt, curator at the Diptera collection of the NHM, London. I wish herewith to express my gratitude for the great support of my studies on Muscidae that he granted me in the recent years. Be it at my visits to the collection of the London Museum, or be it for sending materials for comparative studies or for the work on unidentified specimens, it was always a great help.

The species name wyatti is a noun in genitive case.

Diagnosis: Due to the white anterior spiracle and the brownish lower calypter the small male of Curranosia wyatti spec. nov. leads in the Curranosia key (ZIELKE 1971a) to a subspecies of Curranosia spekei (JAENNICKE, 1867), namely Curranosia s. pilarara (SNYDER, 1951). The new species, however, is clearly distinguished from this subspecies by the shining green mesonotum lacking any dusted markings, the presence of $1+3$ katepisternal setae and the clearly hyaline wing membrane. Apart from the distinctly larger body size of six and more $\mathrm{mm}$, the presutural surface of the mesonotum of the C. s. pilarara male is marked at least with a dusted patch, there are $1+2$ katepisternals and the wing membrane has a distinct brownish shine.

\section{Discussion}

Of the seven species hitherto known of the genus six are characterized with brown anterior spiracles, Curranosia spekei s.l. is the only species with striking white anterior spiracles. Both newly described species also have white spiracles, showing that this feature is not an exception in the genus. Curranosia wyatti is differentiated from other species by differences of features which are commonly found at the genus, for example absence or presence of white pollinose markings on presutural part of mesonotum and different numbers of the large body-setae. Curranosia vanemdeni however is mainly characterized by features which have not been reported until now from Curranosia species, such as protruding mouthparts, very slender proboscis and mid tibia with an anterior seta. That might also be a reason why van Emden did not determine in 1940 the specimen down to species level. At that time the genus Curranosia was not described yet. According to Malloch (1923) species of Orthellia (now Neomyia) could be separated from species of the genus Pyrellia RobineAu-Desvoidy, 1830 by the presence of setulae on the posterior part of the suprasquamal ridge which were usually black and strongly developed. The setulae of C. vanemdeni however are yellowish-golden and they might not be immediately recognized at first glance, as is the case with strong dark setae. If the finer not contrasting setae had been overlooked it would explain why the specimen was not assigned to the genus Orthellia. Another character, so far not observed in species of Curranosia and African Neomyia, is the anterior seta of the mid tibia. However, several species of the genus Pyrellia have an anterior seta present on mid tibia, and this could perhaps explain why C. vanemdeni was provisionally assigned to Pyrellia.

With the description of Curranosia vanemdeni spec. nov. and Curranosia wyatti spec. nov. the number of species of the genus is raised now to nine species.

\section{Acknowledgements}

I am very grateful to Nigel Wyatt, curator at the Diptera collection of the Department of Life Sciences of The Natural History Museum, London for making the Curranosia specimens available for my studies. I also have to thank Toshko Ljubomirov, responsible for the Zoological collection of the Institute of Biodiversity and Ecosystem Research, Sofia for giving me generous access to the Diptera collection and for providing all facilities needed for the study of Muscidae. My thanks are also due to an anonymous reviewer for helpful comments for the improvement of this contribution and to Dr. John Deeming (Cardiff) who kindly proof-read the manuscript.

\section{References}

Gregor, F.; Rozkošny, R.; Barták, M. \& Vaňhara, J. 2016: Manual of Central European Muscidae (Diptera). - Zoologica 162: 1-220.

Malloch, J. R. 1923: Exotic Muscaridae (Diptera). XI. Annals and Magazine of Natural History 12 (9): 505-528.

Ninei, S. S. \& de Carvalho, C. J. B. 2009: The Muscini flies of the world (Diptera, Muscidae): identification key and generic diagnoses. - Zootaxa 1976: 1-24.

Paterson, H. E. 1957: A new genus and two new species of Muscini from South Africa. (Diptera: Muscidae). Journal of the Entomological Society of South Africa, Pretoria 20: 445-449.

Pont, A. C. 1980: Family Muscidae. - In: Crosskey, R. W. (ed.) 1980: Catalogue of the Diptera of the Afrotropical Region. - British Museum (Natural History), London, UK: 721-761.

ZIELKe, E. 1971a: Revision der Muscinae der äthiopischen Region. - Series Entomologica 7: 1-199.

Zielke, E. 1971b: Muscinae vom südlichen Afrika. Zoologischer Anzeiger, Leipzig 187: 214-218.

ZIELKE, E. 1972: Beitrag zur Kenntnis der Verbreitung afrikanischer Musciden (Muscidae; Diptera). Teil II: Canadian National Collection of Insects. - Zeitschrift für angewandte Zoologie, Berlin 59: 361-375.

ZIELKE, E. 1974: Beitrag zur Kenntnis der Verbreitung afrikanischer Musciden (Muscidae; Diptera). Teil III: Sammlung der California Academy of Sciences. Zeitschrift für angewandte Zoologie, Berlin 61: 1-44. 